\title{
Young Patient with Chagas Disease Presenting Initially as Acute Chest Pain and Treated for Acute Coronary Syndrome
}

\author{
Paciente Jovem com Doença de Chagas, Apresentando como Sintoma Inicial Dor Torácica Típica e Aguda, \\ Entrando em Linha de Cuidado para Síndrome Coronariana Aguda
}

Jakson Ferreira Neto ${ }^{1}$, Dannyl Roosevelt de Vasconcelos Lima ${ }^{1}$, Pedro Vinicius Amorim de Medeiros Patriota ${ }^{1}$, João Helbert Costa e Silva ${ }^{1}$, Antônio Marconi Leandro da Silva' ${ }^{1}$, Anderson da Costa Armstrong ${ }^{1}$

Federal University of Vale do São Francisco, Petrolina, PE, Brazil.

\section{Introduction}

Chagas disease, a chronic and endemic condition in 21 countries within the Americas, affects approximately 6 million people. ${ }^{1}$ The northeast region has always been particularly important for the disease. According to data from the Mortality Information System (Sistema de Informação sobre Mortalidade), between 1980 and 2007, Brazil registered 156,224 deaths from Chagas disease; of them, 20,472 were in the northeast region and 3,144 occurred in Pernambuco. ${ }^{2}$

Classic symptoms of Chagas disease can include chest pain, commonly typical for angina. Records of Chagas patients usually relate typical acute anginal pain to superimposed coronary artery disease. However, microcirculation disease has also been suggested as a chest pain trigger. ${ }^{3}$ Despite the high prevalence of Chagas heart disease in inland northeastern Brazil, coronary artery disease remains the main cause of heart failure and acute coronary syndromes.

This report describes a rare presentation of a neglected disease with a high regional prevalence. Thus, it reports the clinical condition and complementary tests of a young patient who presented with typical and acute anginal chest pain who entered the line of care for acute coronary syndrome.

\section{Case report}

Our patient was a 38-year-old man, a high-voltage electrician commonly working in rural areas inland within the northeast region and living in an urban area with good sanitary conditions, with hypertension and type 2 diabetes. The patient was admitted to the emergency room complaining of severe oppressive retrosternal pain triggered by exertion and associated with vertigo that started seven hours before admission. He reported experiencing a similar condition in the previous week with lower intensity that was triggered by exertion and improved with rest. He presented no significant changes on clinical examination.

\section{Keywords}

Chagas cardiomyopathy; Chagas disease; Chest pain.

Mailing Address: Jakson Ferreira Neto •

Rua Juazeiro, 280, Condomínio Terras Alphaville, Boa Esperança,

CEP 56327-020, Petrolina, PE, Brazil.

E-mail: jaksonmed@hotmail.com

Manuscript received 5/7/2021; revised 7/16/2021; accepted 8/27/2021

DOI: 10.47593/2675-312X/20213404eabc206
A care line for acute coronary syndrome was defined, with an electrocardiogram (ECG) on admission showing no changes and high-sensitivity troponin testing negative (Figure 1). Transthoracic echocardiography showed a slightly increased left atrial volume $\left(36 \mathrm{~mL} / \mathrm{m}^{2}\right)$, preserved right ventricular (RV) size and systolic function, tricuspid annular plane systolic excursion (TAPSE) of $22 \mathrm{~mm}$, borderline left ventricular (LV) size and function (diastolic, 56 mm; systolic, 39 $\mathrm{mm}$; indexed LV mass of $104 \mathrm{~g} / \mathrm{m}^{2}$; and left ventricular ejection fraction [LVEF], 56\%), and no identifiable contractility changes.

Low-risk unstable angina was suspected. A noninvasive stratification performed by myocardial perfusion scintigraphy (Figure 2) showed hypoperfusion in reversible stress at rest in the anterior (mid and apical), lower (mid and basal), and LV apex segments. During the physical stress phase, the patient reported mild intensity retrosternal chest pain at peak effort and gradual relief during recovery. A subsequent coronary angiography showed no obstructive lesions in the epicardial coronary arteries (Video 1 and 2).

Cardiac magnetic resonance (CMR) (Figure 3 and Video 3) showed left atrial enlargement, an increased LV size, and mild global dysfunction (LVEF of 48\%) with an area of dyskinesia in the apex and diffuse hypokinesia predominantly in the inferolateral wall. The presence of trabeculation was noted in the apical region with an aspect of non-compacted myocardium (NCM) and an $\mathrm{NCM}$ /compacted myocardium (MC) ratio of 3.04 in the lateral (apical) segment. Perfusion changes were noted at rest in the inferolateral wall along with an endocardial pattern of delayed enhancement occupying about 50\% of the lateral segment (apical) and $>50 \%$ of the inferolateral segments (mid and basal).

Serology for Chagas disease by the chemiluminescence method was positive and confirmed by indirect immunofluorescence at a titration of $1: 80$. Finally, the patient was diagnosed with chest pain due to Chagas heart disease. Medical anamnesis usually attributes epidemiologically suspected Chagas disease to living in a mud house. However, in endemic areas, the risk of exposure can be occupational, as in the case described here.

\section{Discussion}

Diabetes and hypertension, as in the case reported here, significantly increase a patient's risk of coronary artery disease due to its potential severity and high prevalence. In Brazil, ischemic heart disease is the leading cause of death, accounting for $31 \%$ of cardiovascular deaths. ${ }^{4}$ Typical acute pain as the first presentation of Chagas heart disease is rare. 


\section{Case Report}

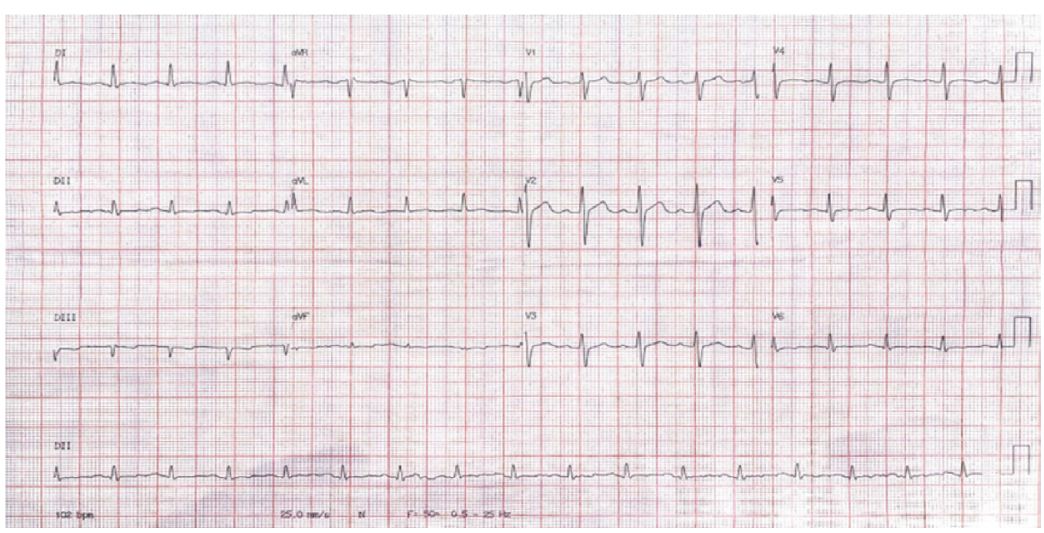

Figure 1 - Electrocardiogram performed during emergency care.

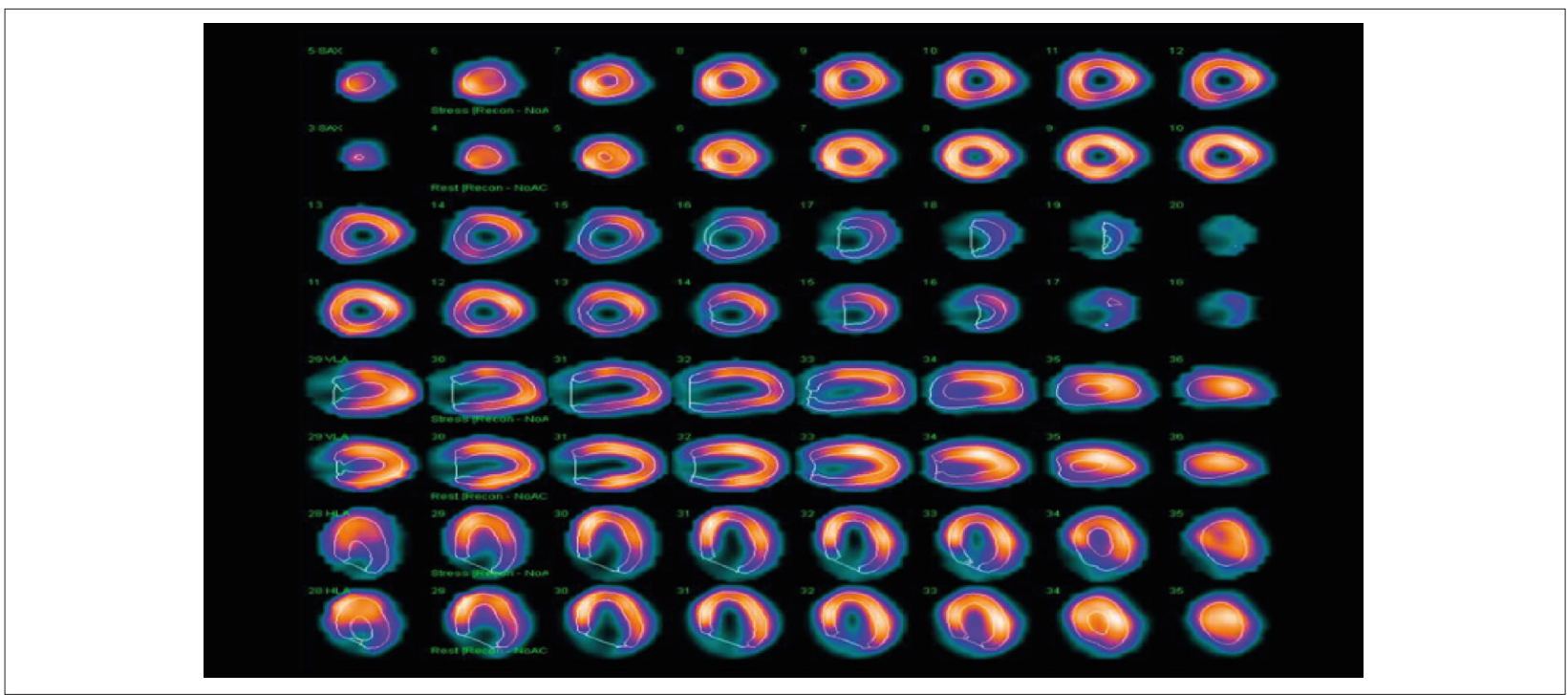

Figure 2-Myocardial scintigram showing perfusion at rest versus physical stress. Reduced marker uptake is evident on the anterior, lower, and left ventricular apex segments.

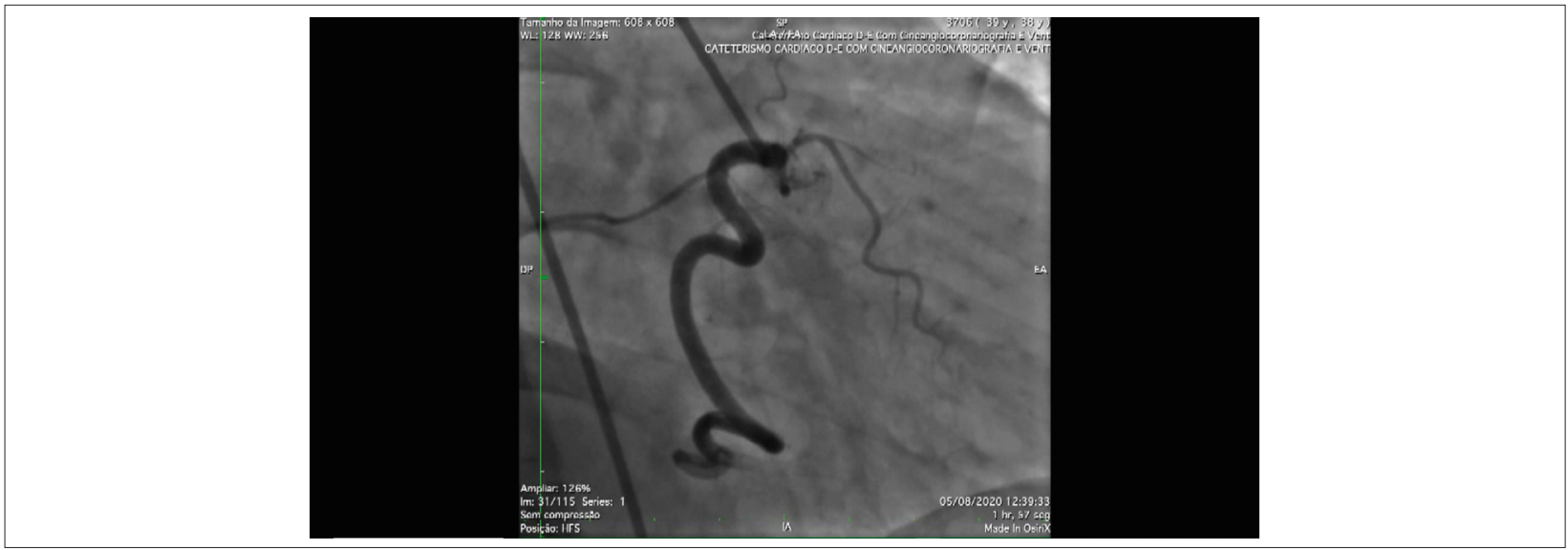

Video 1 - Right Coronary Artery. 


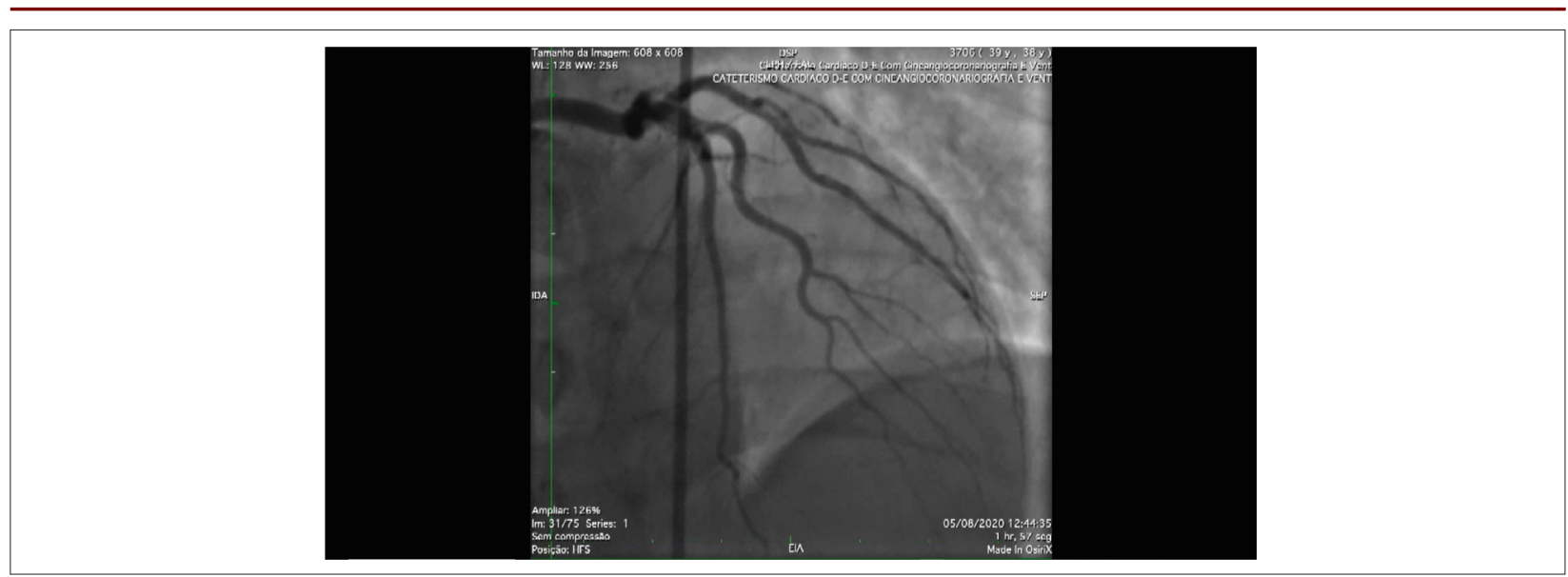

Video 2 - Left Coronary Artery.

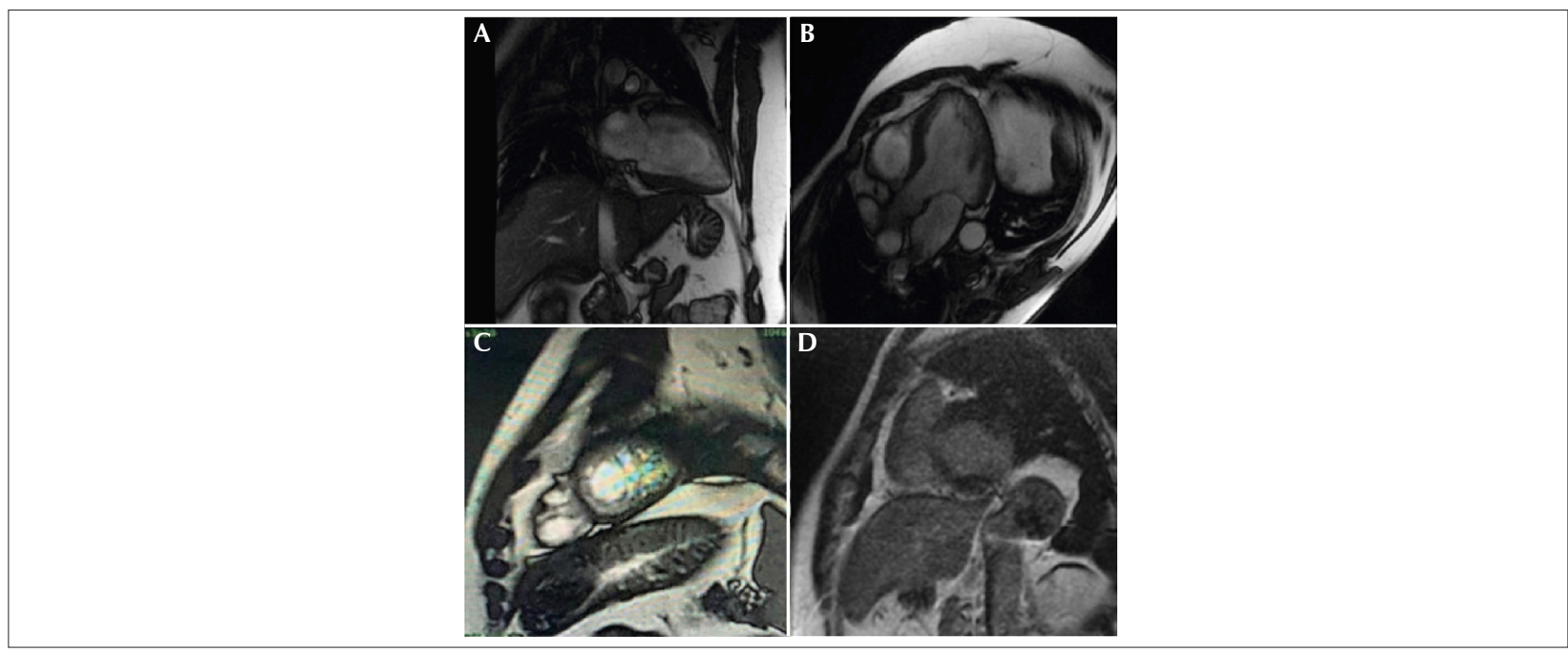

Figure 3 - Cardiac magnetic resonance image. (A) Two-chamber steady-state free precession cine image showing trabeculation and apical aneurysm (with a glove finger appearance): (B) Three-chamber steady-state free precession cine image showing trabeculation in the inferolateral myocardium; (C) Steady-state free precession cine imaging of the left and right ventricular short axis (apical section) showing trabeculation with a non-compacted myocardium/compacted myocardium ratio > 3.0; (D) short-axis delayed enhancement showing an area of fibrosis.

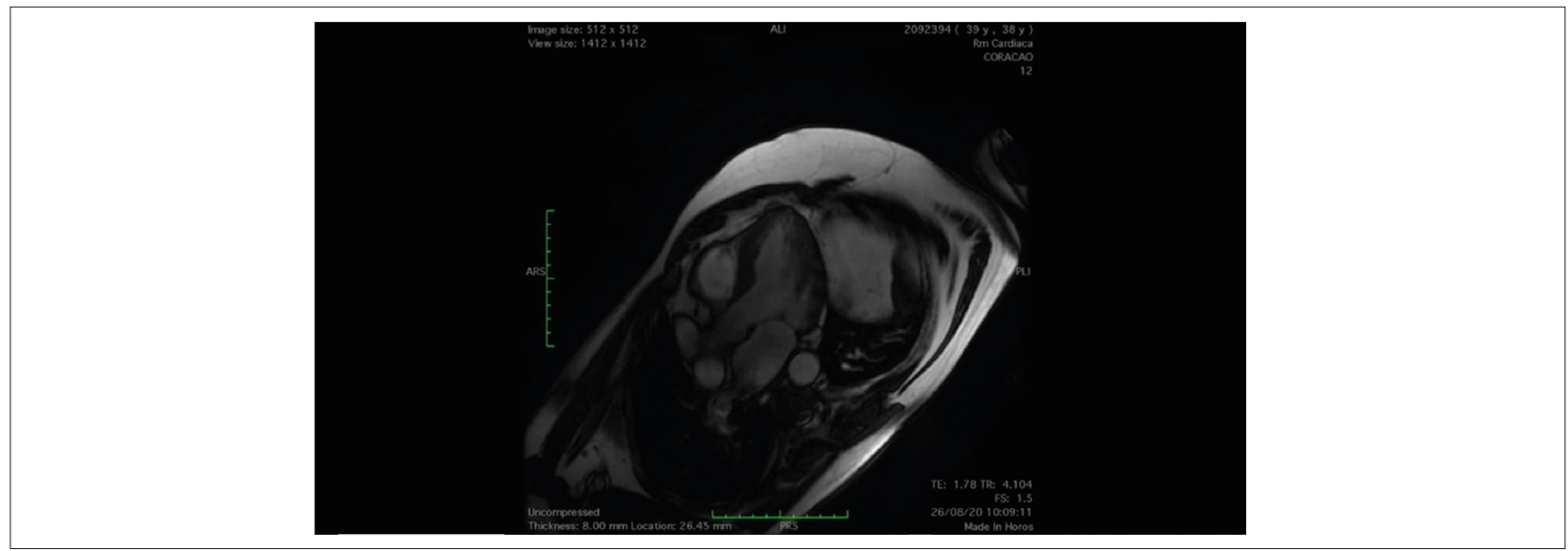

Video 3 - Cardiac Magnetic Resonance Imaging (CMR) showing an enlarged LA, increased LV dimensions, mild global dysfunction, with an area of dyskinesia in the apex and diffuse hypokinesia. 
Cardiac changes in Chagas disease include tapered ventricular walls, biventricular enlargement, apical aneurysm, and mural thrombi, which may progress with signs of perfusion defects. The findings are possibly explained by the occurrence of microthrombus formation associated with microcirculatory spasms, endothelial dysfunction, and increased platelet activity. ${ }^{3}$

Chest pain, commonly atypical, may be present in patients with Chagas disease. Conditions similar to those of angina pectoris can occasionally occur, being apparently related to microvascular changes including microthrombus formation, microcirculatory spasm, endothelial dysfunction, and increased platelet activity. ${ }^{5}$ Microcirculatory changes seem to amplify the inflammatory process and cause myocardial ischemia, although the subepicardial coronary vessels usually show no significant obstructions as reported here. ${ }^{3}$ Microcirculation changes commonly cause myocardial hypoperfusion in some areas naturally irrigated by fewer coronary branches, which are more prone to aneurysm formation in the apical and posterior-basal LV walls. ${ }^{6}$

CMR enables an accurate morphofunctional analysis that can be very informative, even in cases in which the echocardiographic image is inconclusive. It has great value in the detection of changes in ventricular geometry, such as the glove finger aneurysm (apical ventricular), a typical finding of Chagas cardiomyopathy. ${ }^{7}$ More recent studies highlight the potential of CMR to detect myocardial fibrosis regions in patients with Chagas cardiomyopathy and be a potentially valuable tool for these patients in the noninvasive risk prediction of sudden death, even in those with a preserved LVEF. $^{8}$ The pattern of fibrotic involvement varies, with the presence of diffusely distributed, focal, and even transmural involvement simulating an area of fibrosis usually seen in myocardial infarction due to obstructive coronary disease as reported here. ${ }^{9}$

\section{References}

1. Pan American Helath Organization (PAHO). Chagas disease. [cited 2021 Sep. 30]. Available from: https://www.paho.org/hq/ index.php?option=com_ topics\&view=article\&id=10\&l temid=40743\&lang=en.

2. Braz SC, Melo MF, Lorena VM, Souza WV, Gomes YM. Doença de Chagas no Estado de Pernambuco, Brasil: análise de séries históricas das internações e da mortalidade. Rev Soc Bras Med Trop. 2011;44(3):318-23.

3. Marin-Neto JA, Simões MV, Syres-Neto EM, Sttab-Santos JL, Gallo Júnior L, Amorim DS, et al. Studies of the coronary circulation in Chagas' heart disease. são Paulo Med J. 1995;113(2). doi: http://dx.doi.org/10.1590/ S1516-31801995000200014.

4. Ribeiro AL, Duncan BB, Brant LC, Lotufo PA, Mill JG, Barreto SM. Cardiovascular Health in Brazil: Trends and Perspectives. Circulation. 2016;133(4):422-33. doi: 10.1161/CIRCULATIONAHA.114.008727.

5. Rossi MA. Microvascular changes as a cause of chronic cardiomyopathy in Chagas' disease. Am Heart J. 1990;120(1):233-6. doi: 10.1016/00028703(90)90191-y.
A pattern similar to that of NCM has been reported for Chagas heart disease. ${ }^{10}$ Some characteristics are important to differentiating the etiology of myocardial involvement, including the presence of apical aneurysm (common in Chagas cardiomyopathy but unlikely in non-compaction) and the presence of transmural or epicardial fibrosis (more common in NCM, while in Chagas disease, the fibrosis tends to be subendocardial and adjacent to the trabeculation).

In the case reported here, the presence of this pattern of fibrosis that lacked a direct correlation with the typical acute chest pain on admission but was associated with the other CMR findings (more typical of Chagas heart disease) suggests that the myriad of findings are, in fact, related to changes resulting from Chagas disease.

In this case report, a young patient with previously unknown Chagas heart disease presented with unusual acute coronary syndrome. These findings confirm the need to consider the diagnosis of Chagas disease in cases of chest pain with consideration of the epidemiological profile of the region.

\section{Authors' contributions}

Data collection: DRV Lima, JF Neto, JHC Silva, and PVAM Patriota; manuscript writing: JF Neto; critical review of the manuscript for important intellectual content: AML Silva and AC Armstrong.

\section{Conflict of interest}

The authors have declared that they have no conflict of interest.

6. Higuchi Mde L, Benvenuti LA, Martins Reis M, Metzger M. Pathophysiology of the heart in Chagas' disease: current status and new developments. Cardiovasc Res. 2003;60(1):96-107. doi: 10.1016/s0008-6363(03)00361-4.

7. Pacheco AB, Melo RJ, Rochitte CE. Cardiac Magnetic Resonance in the Assessment of Chagas Disease and its Complications. Int J Cardiovasc Sci. 2020;33(6):705-12.

8. Schmidt A, Romano MM, Maciel BC, Marin-Neto JA. Cardiac magnetic resonance imaging for sudden cardiac death: much more than another method to measure LVEF. Current Cardiovascular Imaging Reports. 2013;6:431-4. doi: http://dx.doi.org/10.1007/s12410-013-9231-3.

9. Simões MV, Romano MM, Schmidt A, Martins KS, Marin-Neto JA. Cardiomiopatia da Doença de Chagas. Int J Cardiovasc Sci. 2018;31(2):17389. doi: https://doi.org/10.5935/2359-4802.20180011.

10. Weiford BC, Subbarao VD, Mulhern KM. Noncompaction of the ventricular myocardium. Circulation. 2004;109 (24):2965-71. 